\title{
Groundwater Potential Assessment Using Vertical Electrical Sounding and Magnetic Methods: A Case of Adilo Catchment, South Nations, Nationalities and Peoples Regional Government, Ethiopia
}

\author{
Mulugeta Markos, ${ }^{1}$ Abel Saka, ${ }^{1}$ Leta Tesfaye Jule, ${ }^{1,2}$ N. Nagaprasad $\left(\mathbb{D},{ }^{3}\right.$ \\ and Krishnaraj Ramaswamy $\mathbb{D}^{2,4}$ \\ ${ }^{1}$ Department of Physics, Dambi Dollo University, Dambi Dollo, Ethiopia \\ ${ }^{2}$ Centre for Excellence-Indigenous Knowledge, Innovative Technology Transfer and Enterpreneurship, Dambi Dollo University, \\ Dambi Dollo, Ethiopia \\ ${ }^{3}$ Department of Mechanical Engineering, ULTRA College of Engineering and Technology, Madurai 625 107, Tamil Nadu, India \\ ${ }^{4}$ Department of Mechanical Engineering, Dambi Dollo University, Dambi Dollo, Ethiopia
}

Correspondence should be addressed to Krishnaraj Ramaswamy; prof.dr.krishnaraj@dadu.edu.et

Received 24 July 2021; Accepted 19 October 2021; Published 8 December 2021

Academic Editor: Maria Atanassova

Copyright (c) 2021 Mulugeta Markos et al. This is an open access article distributed under the Creative Commons Attribution License, which permits unrestricted use, distribution, and reproduction in any medium, provided the original work is properly cited.

\begin{abstract}
Vertical electrical sounding and magnetic methods were carried out to assess groundwater potential in Adilo catchment, Kembata Tembaro Zone, South Nations, Nationalities and Peoples Regional Government, Main Ethiopian Rift. The data were acquired from eight VES points using Schlumberger electrode arrays with maximum half current electrode spacing $(\mathrm{AB} / 2=500)$ and 253 magnetic data points were analyzed. The qualitative analysis of VES data was accomplished by using curves, apparent resistivity, and pseudodepths, and the quantitative interpretations of the VES data were constructed by the VES data using IPI-Res3, IPI2Win, and surfer software and constructing geoelectric section along with profiles and lithological information from the borehole and Geosoft interpretation was used for magnetic data. The VES results of the data revealed five geoelectric layers which differ in degree of fracturing, weathering, and formation. The upward continued magnetic field map anomaly to $560 \mathrm{~m}$ illustrated northwestern to the southwest; areas have a low magnetic anomaly. Examining the potential aquifer of profile one's geoelectric section, the horizons of layer four were better potential aquifers as the highly fractured and weathered ignimbrite zone of layer five of VES13 was $219 \mathrm{~m}$ deeper than the depths of the other VES points, and along with profile two geoelectric sections, the horizon of layer four VES23 layer five has the lowest resistivity with large thickness at a depth of $253 \mathrm{~m}$. Thus, the low resistivity and the large thickness of these formations are an indication of the high yield of groundwater potential in the study area.
\end{abstract}

\section{Introduction}

In most cases, drinking water comes from two sources: surface water and groundwater. Surface water sources are bodies of water on the earth's surface, such as rivers, lakes, and reservoirs. Groundwater sources are underground aquifers which are geologic formations containing water underground. Groundwater is accessed by drilling a well into the underground water source and then pumping the well water up to the surface [1-5]. The value of an aquifer as a source of groundwater is a function of the porosity of the geologic stratum or layer, of which it is formed [2, 6-9]. Most of the area is known for the high scarcity of surface water, and due to recurrent drought, a substantial part of the area's water supply coming from groundwater has taken great attention. Although water requirement is increasing very rapidly with the growth of human and animal population in the area, analysis of water resources has been 
fragmentary. Thus, as a part of filling the gap, in the present study, vertical electrical sounding and magnetic methods were used to systematically assess the importance of each input parameter in the assessment of groundwater potential in the study catchment. Due to the above reasons, the search for groundwater is vital as an immediate and sustainable solution to alleviate the scarcity of water for drinking and other domestic uses in the Adilo catchment. Population growth and economic progress required greater volumes of freshwater [10]. Therefore, the detailed geophysical study for the assessment of groundwater potential is important.

1.1. Local Geology of the Study Area. The study area is covered by thick soils, except river cut and road section. The local geologic setup of the study area was described based on the observations of the river cut, boreholes, and drainage network patterns and illustrated in Figure 1. Stratigraphy of the study sites is clay, volcanic ash, gravel, and ignimbrite. The ignimbrite found in the southern portion of the study area is highly fractured and weathered.

\section{Materials and Method}

2.1. Location and Accessibility. The Adilo catchment, the study area, is situated in the Main Ethiopian Rift. It is located about $130 \mathrm{~km}$ north-west of the regional capital city, Hawassa, and $342 \mathrm{~km}$ away from Addis Ababa through the asphalt road from Addis Ababa to the Arba Minch town that passes via towns of Shashemane and is depicted in Figure 2 Adilo catchment is bounded between UTM coordinates $356496 \mathrm{~m}-428654 \mathrm{~m}$ easting and $799875 \mathrm{~m}-820483 \mathrm{~m}$ northing and about $1938 \mathrm{~m}$ above sea level. Locally, the study area is located east-north of Durame town of Kembata Tembaro Zone in Southern Regional State along the Main Asphalt Road, Addis Ababa, to Alaba Kulito-Wolaita Sodo of SNNPR and is situated $13 \mathrm{~km}$ from Durame town [11-14].

2.2. Electrical Resistivity Data Acquisition. The Schlumberger array is mostly used in vertical electrical sounding for its better depth penetration, and it is less sensitive for lateral inhomogeneities. The potential electrodes remain fixed during a number of successive measurements with expanding current electrodes. For this study, the symmetrical Schlumberger array, which is the vertical electrical sounding (VES), was conducted along four lines which are about $200 \mathrm{~m}$ apart. The VES were carried out with maximum current electrode spacing $(\mathrm{AB} / 2)$ of $500 \mathrm{~m}$ by injecting electrical current into the ground by means of two outer electrodes, and the resulting potential difference was measured by the second pair of potential electrodes situated in the center of the potential electrodes. The current electrode spacing selected for these surveys was $A B / 2$ (in meter): $1.5 \mathrm{~m}$, $2.1 \mathrm{~m}, 3 \mathrm{~m}, 4.2 \mathrm{~m}, 6 \mathrm{~m}, 9 \mathrm{~m}, 13.5 \mathrm{~m}, 20 \mathrm{~m}, 30 \mathrm{~m}, 45 \mathrm{~m}, 66 \mathrm{~m}$, $100 \mathrm{~m}, 150 \mathrm{~m}, 220 \mathrm{~m}, 330 \mathrm{~m}$, and $500 \mathrm{~m}$, and the spacing of the potential electrodes was MN/2 (in meter): $0.5 \mathrm{~m}, 6 \mathrm{~m}$, and $45 \mathrm{~m}$. The repeated calibrations are taken at $20 \mathrm{~m}, 30 \mathrm{~m}$, $150 \mathrm{~m}$, and $220 \mathrm{~m}$ in order to remove the ambiguity of inhomogeneity. The material used at field survey for data collection of magnetic field and resistivity is described as the following.

2.3. Magnetic Field Procedures and Data Acquisition. Before establishing a base station around each profile, the first thing that the researcher does is to look for an appropriate location with less magnetic noise, such as cars and houses with iron roofs. As the survey progresses, the base station must be reoccupied every half of an hour in order to compile a diurnal variation curve for later correction [15]. The magnetic survey was carried out on four parallel profiles, which were nearly $200 \mathrm{~m}$ apart, and field magnetic and VES point locations are shown in Figure 3. These parallels were taken on the same profile from which the VES points were taken within the study area, and magnetic data were collected at every $20 \mathrm{~m}$ interval of the survey points. The positions of the survey stations and station elevations were determined using the Garmin GPS 72H receiver. Magnetic data collection was started and ended by taking base station readings situated around each profile. Hence, there were four base stations, for the first profile BS1 located at a UTM coordinate 388368 easting and 797906 northing, the second profile BS2 at 387482 easting and 798084 northing, the third profile at 387892 easting and 797686 northing, and the fourth profile at 387542 easting and 798318 northing. At each station, the magnetometer reading, recording time, and its location in the UTM coordinate were recorded.

The base station reading for all profiles in time of 1 : 00-1:30 hour was done. The magnetic data acquisitions were employed from north to south along with four profiles. From the site survey total of 253, magnetic data readings were taken manually. The photographic view of vertical electrical sounding is illustrated in Figure 4. Finally, the collected data were imported into computer Excel software for diurnal correction. The profile line and data point of both vertical electrical sounding and magnetic sounding were mapped by ArcGIS 10.3 software together as the following [16-21].

\section{Results and Discussion}

As observed in profile one as follows, this survey consists of four vertical electrical soundings, namely, VES11, VES12, VES13, and VES14. Each VES contains five layers and has different types of curves. It is seen from the interpreted field curves that a very valid correspondence between the field data and the interpreted curves is acquired for all the VES points. The curves of profile one RMS error ranging 0.4-1.56 were obtained from the sounding curves.

Figure 5 shows the electrical resistivity curve of VES11, VES12, VES13, and VES14: (a) interpretation of VES11 curve. This is a curve type and has the lowest resistivity with a large thickness along with layer four which may be interpreted as an aquifer zone. (b) Interpretation of VES12 curve (c) Interpretation of curve of VES13. This curve has the lowest resistivity layer along with layer five and has high 


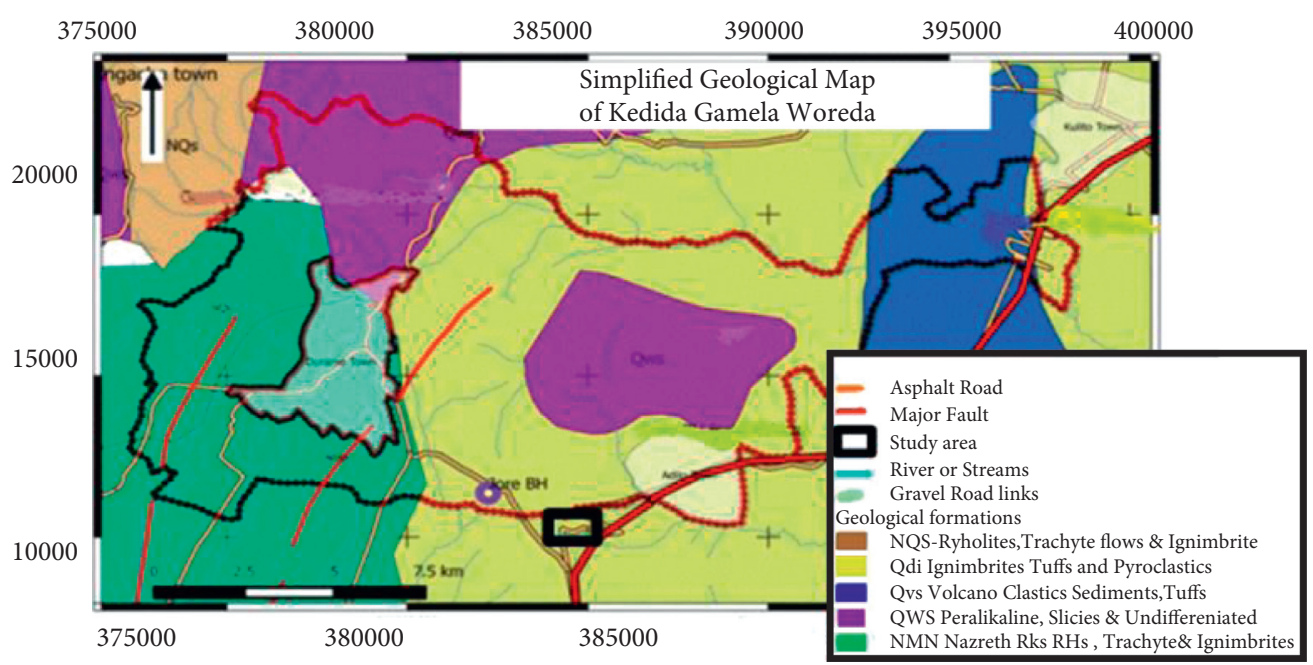

Figure 1: Geological map of the Adilo catchment and its surrounding outcrop from Hosiena geological map $(1: 2,000,000)$.

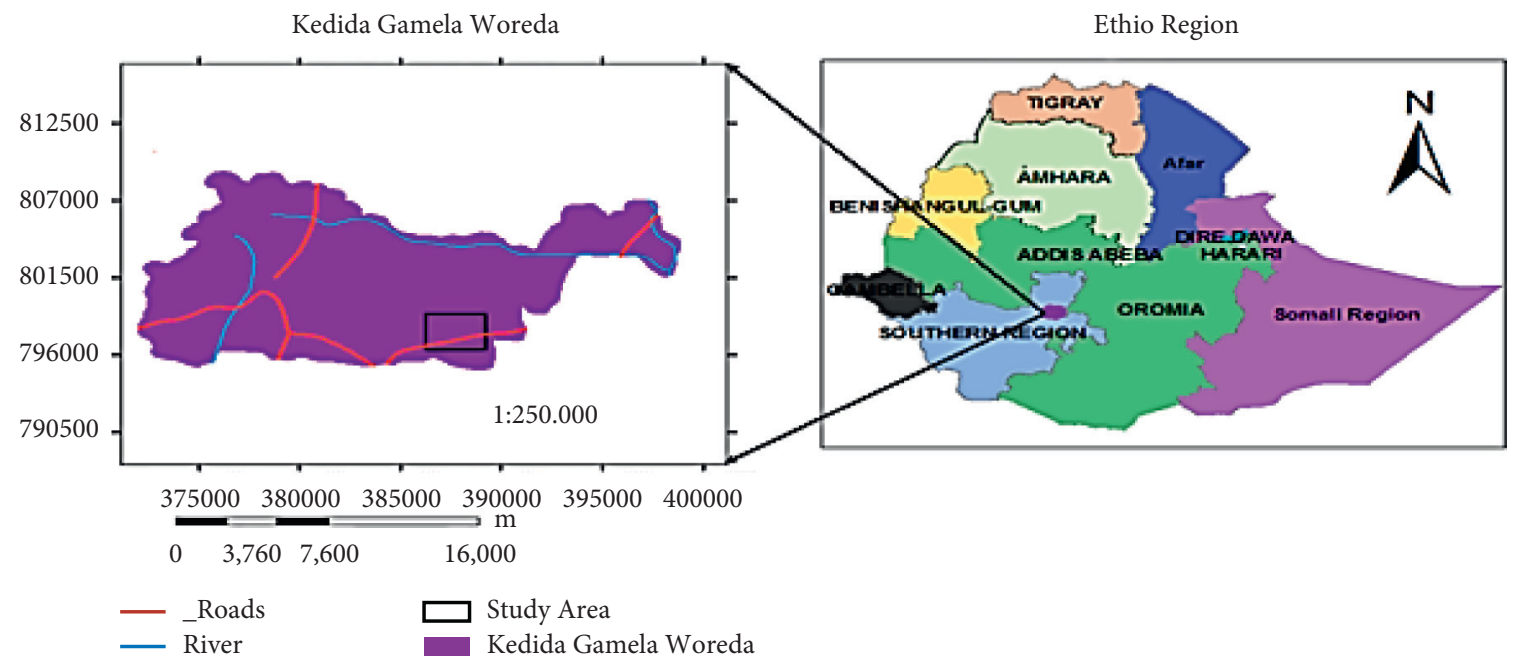

Figure 2: Location map and study area.

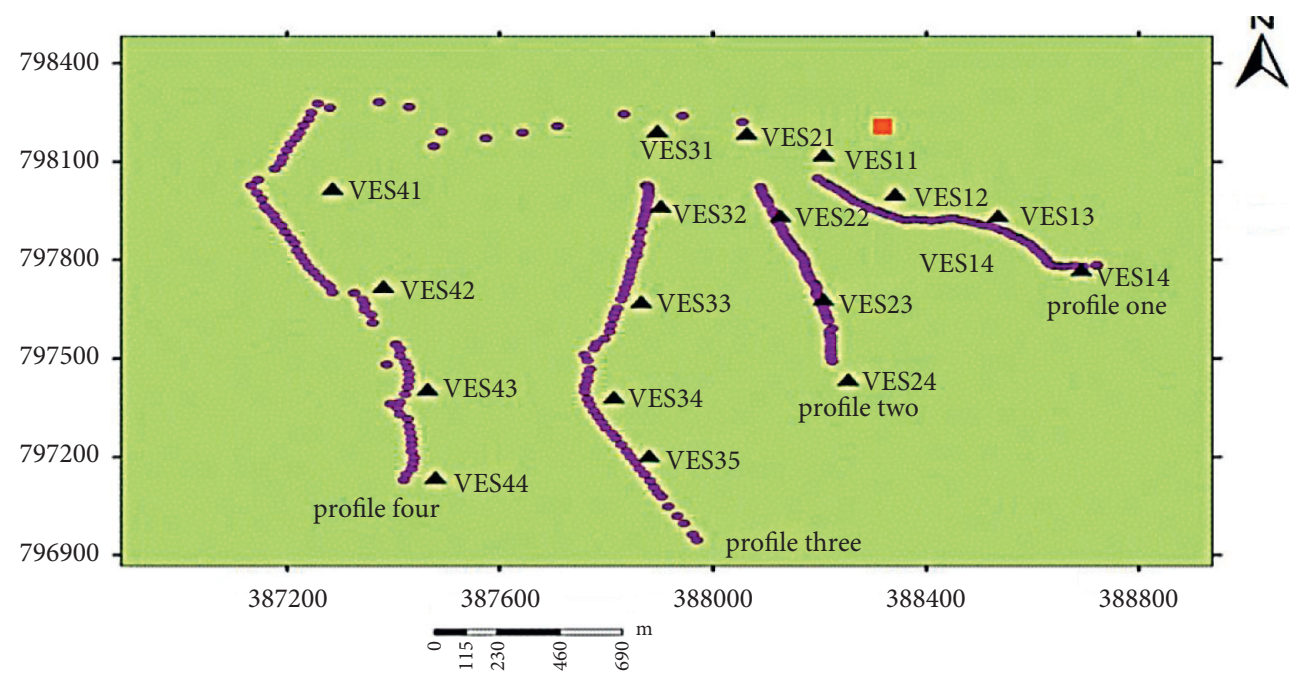

- Borehole

- VES Data Points

- Magnetic Data Points

Figure 3: Field magnetic and VES points. 


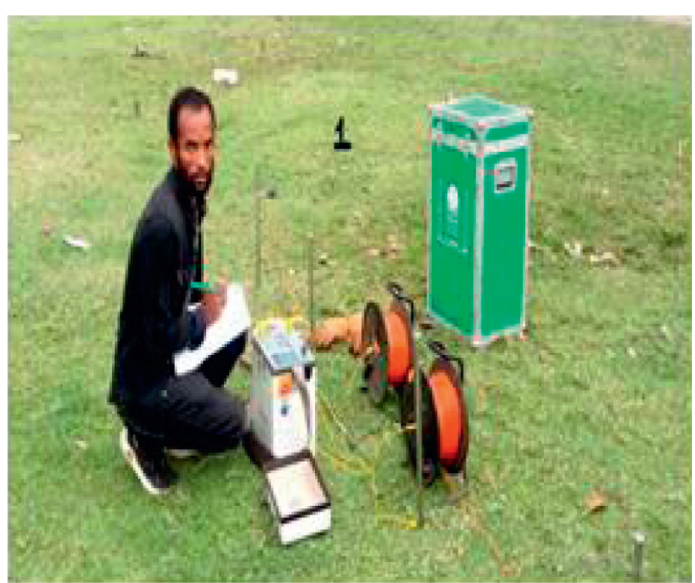

(a)

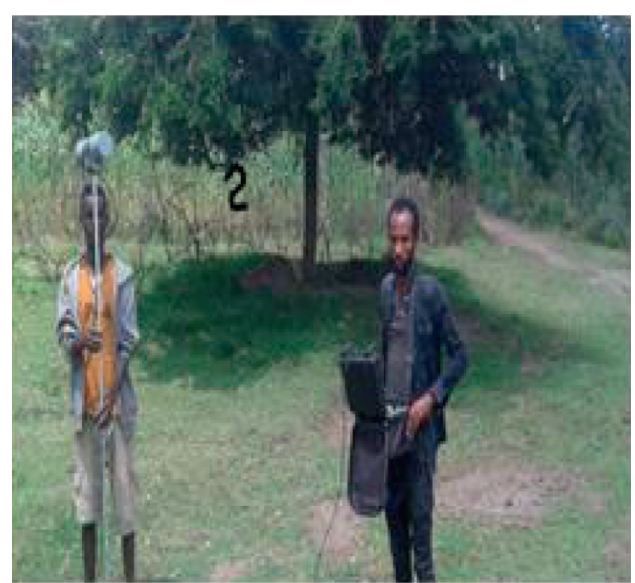

(b)

Figure 4: Photographic view of the vertical electrical (a) sounding and magnetic (b) field operation.
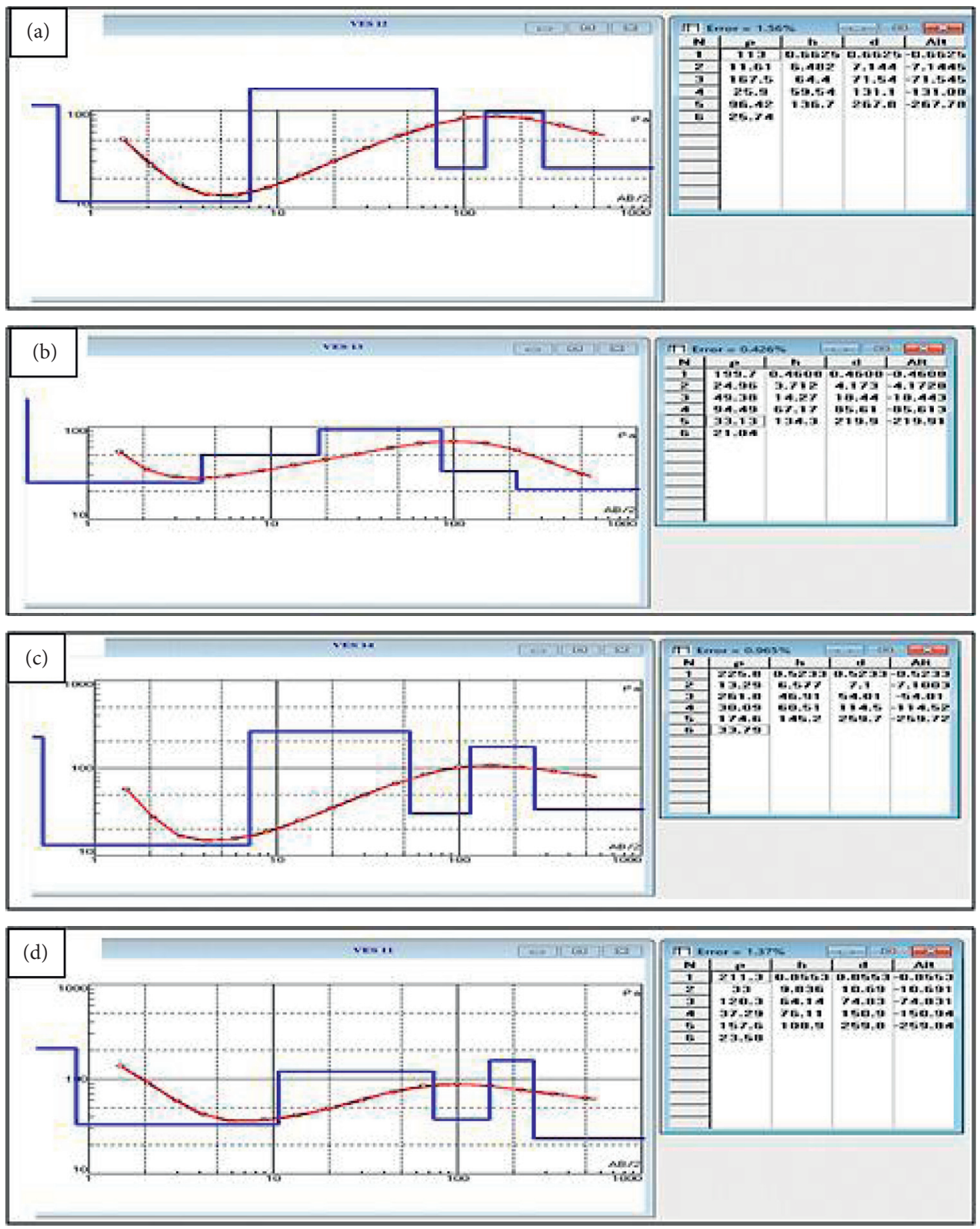

FIGURE 5: (a) Electrical resistivity curve of VES11. (b) Electrical resistivity curve of VES12. (c) Electrical resistivity curve of VES13. (d) Electrical resistivity curve of VES14. 


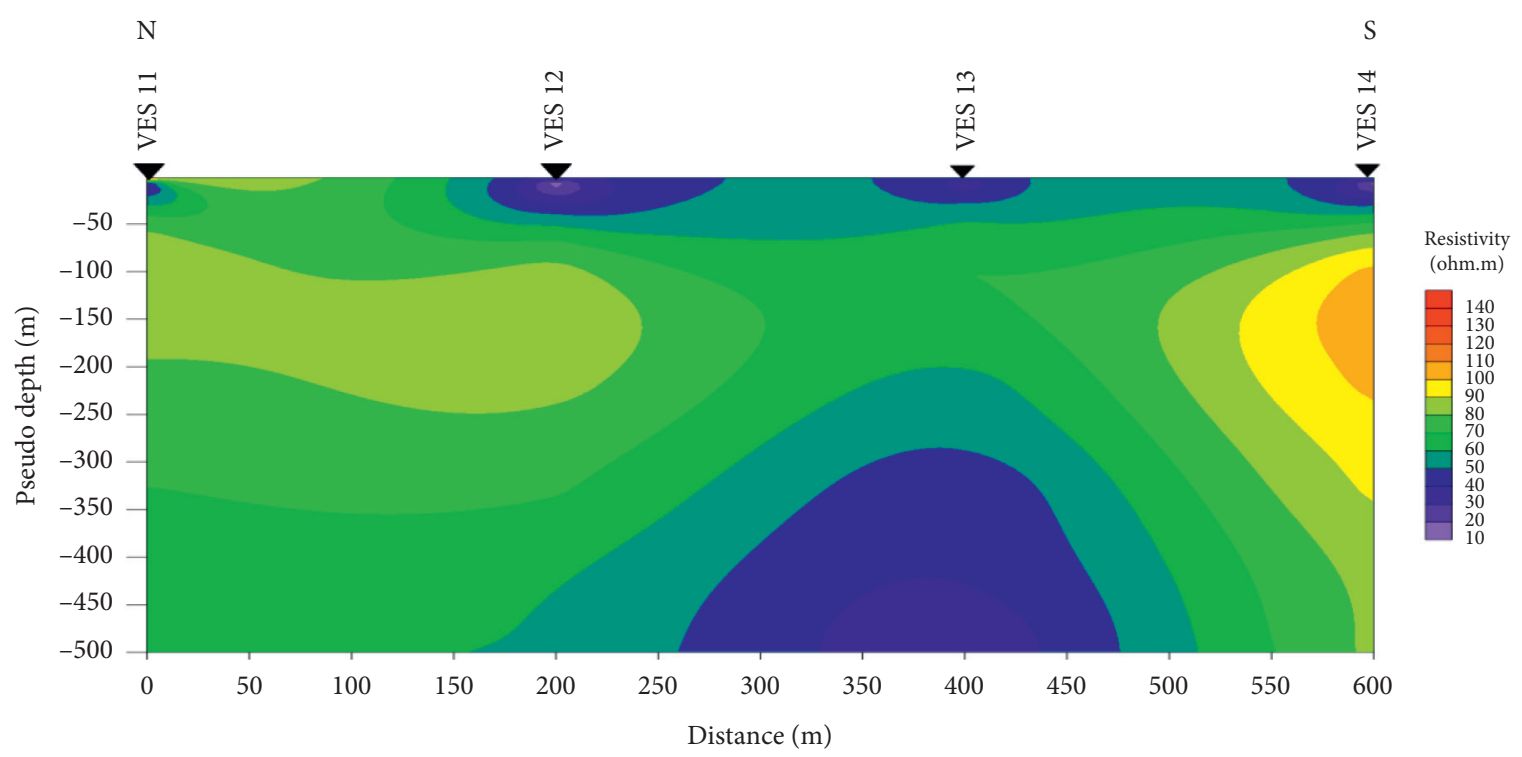

Figure 6: Pseudosection along profile one.

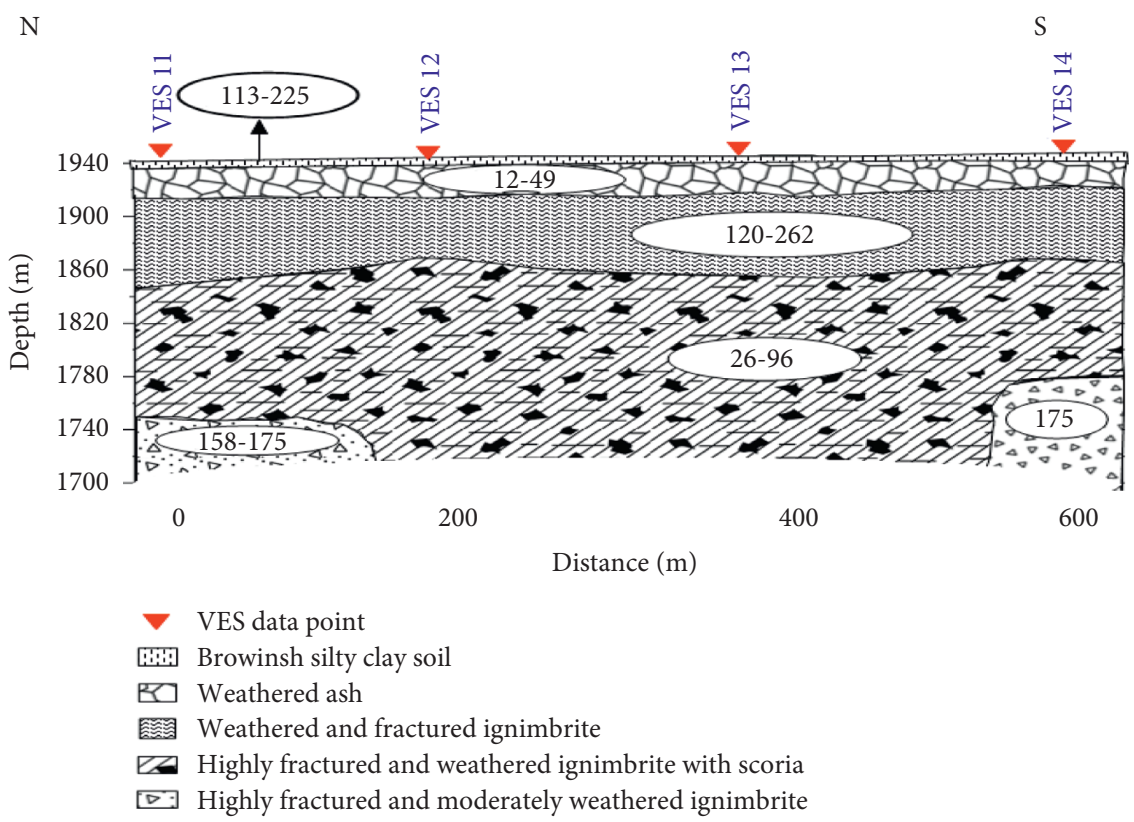

FIgURE 7: Geoelectric sections along with profile one.

thickness. This may indicate high groundwater potential in the study area. (d) Interpretation of the curve of VES14.

3.1. The Pseudosection along with Profile One. The pseudodepth constructed from all VES that lies on profile one is given in Figure 5. Low resistivity responses were found at the bottom depth of VES13 with large thickness. This is interpreted as weak zones within the ignimbrite unit that resulted in low resistivity response due to high weathering and fracturing activities. These are essential results for storing and conducting groundwater potential in the study area.
3.2. Geoelectric Section along with Profile One. The geoelectric section of profile one was constructed, as shown in Figure 6; this profile contains four VES points oriented nearly in the N-S direction. The fourth layer of VES11, VES12, and VES14 and the fifth layer of VES13 profile possess resistivity values ranging from $26-96 \Omega \mathrm{m}$ and thicknesses of $60-134 \mathrm{~m}$. These layers may be highly fractured and weathered ignimbrite with scoria (from borehole data, this is the major aquifer zone). This horizon has a lower resistivity part with a large thickness. Thus, structures having low resistivity and large thickness could be considered as good groundwater potential zones. This layer is probably the major aquifer zone [22-27]. 

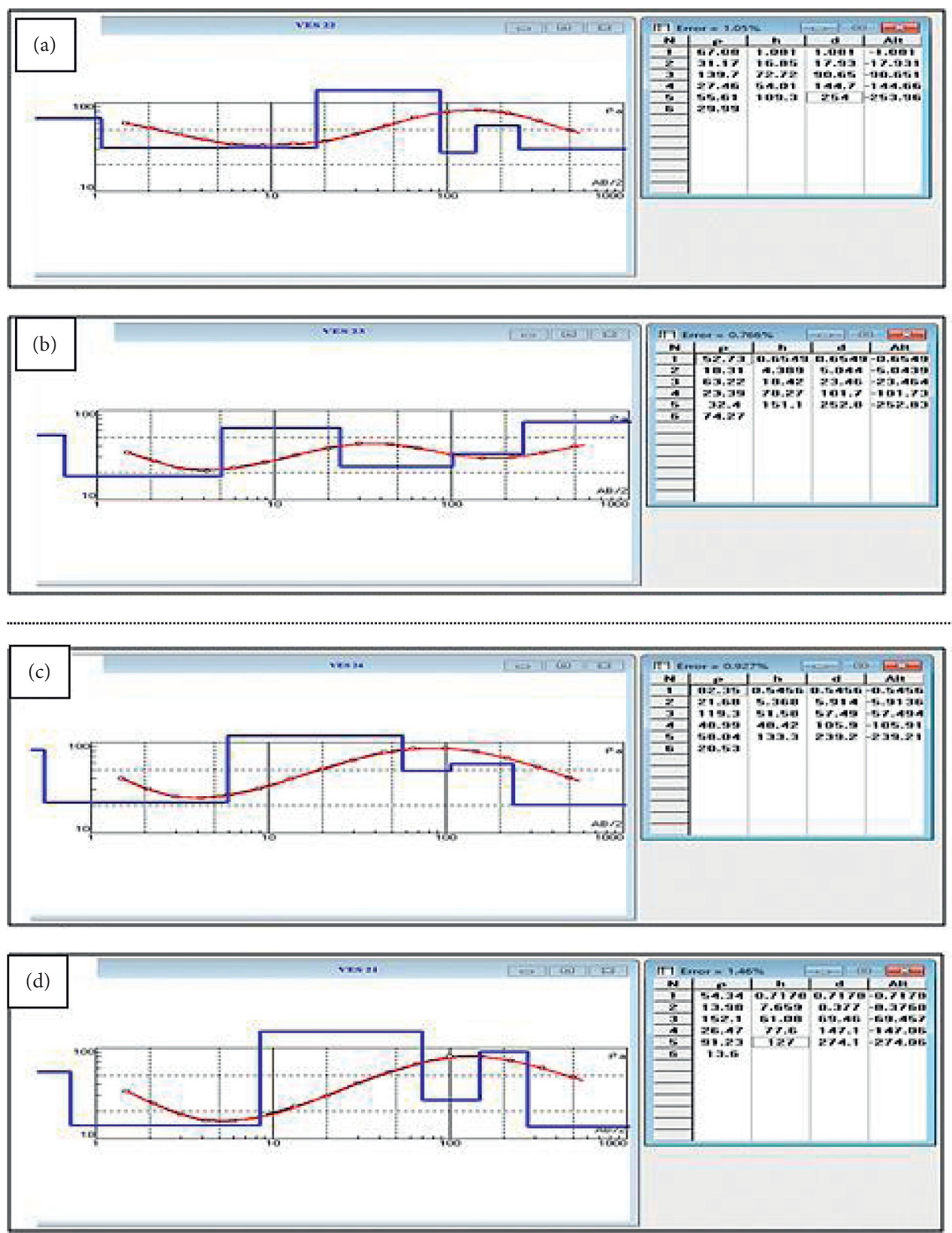

FIgURE 8: (a) Electrical resistivity curve of VES21. (b) Electrical resistivity curve of VES22. (c) Electrical resistivity curve of VES23. (d) Electrical resistivity curve of VES24.

3.3. Curve Interpretation for a Long Profile 2. As observed from Figure 7, profile two consists of four vertical electrical soundings, namely, VES21, VES22, VES23, and VES24. Each VES contains five layers and has different types of curves. After iteration correction and the inversion had been done, the VES22 curve model was produced for the resistivity data as follows. This is an HKH curve type, and its RMS error is about 0.766 [28-31].

3.4. The Pseudosection along with Profile Two. The pseudodepth constructed using VES21 to VES24 that lies on the survey of profile two was described, as shown in Figure 8 Very low resistivity zone was observed at the shallow to a middle depth of VES23, and the area is expected as groundwater saturated zone; it is clearly shown in Figure 9.

3.5. Geoelectric Section along with Profile Two. The geoelectric section of profile two was constructed from the interpreted layer parameters of VES21-VES24 and is shown in Figure 10. The fourth layer of VES21, VES22, and VES23 and the fifth layer of VES23 profile survey possess resistivity values varying from $23-32 \Omega \mathrm{m}$ and thickness of $54-151 \mathrm{~m}$. These were layers interpreted as highly fractured and weathered ignimbrite with scoria. This is a low resistivity horizon with a large thickness which is the result of groundwater saturation in the study area [31]. 


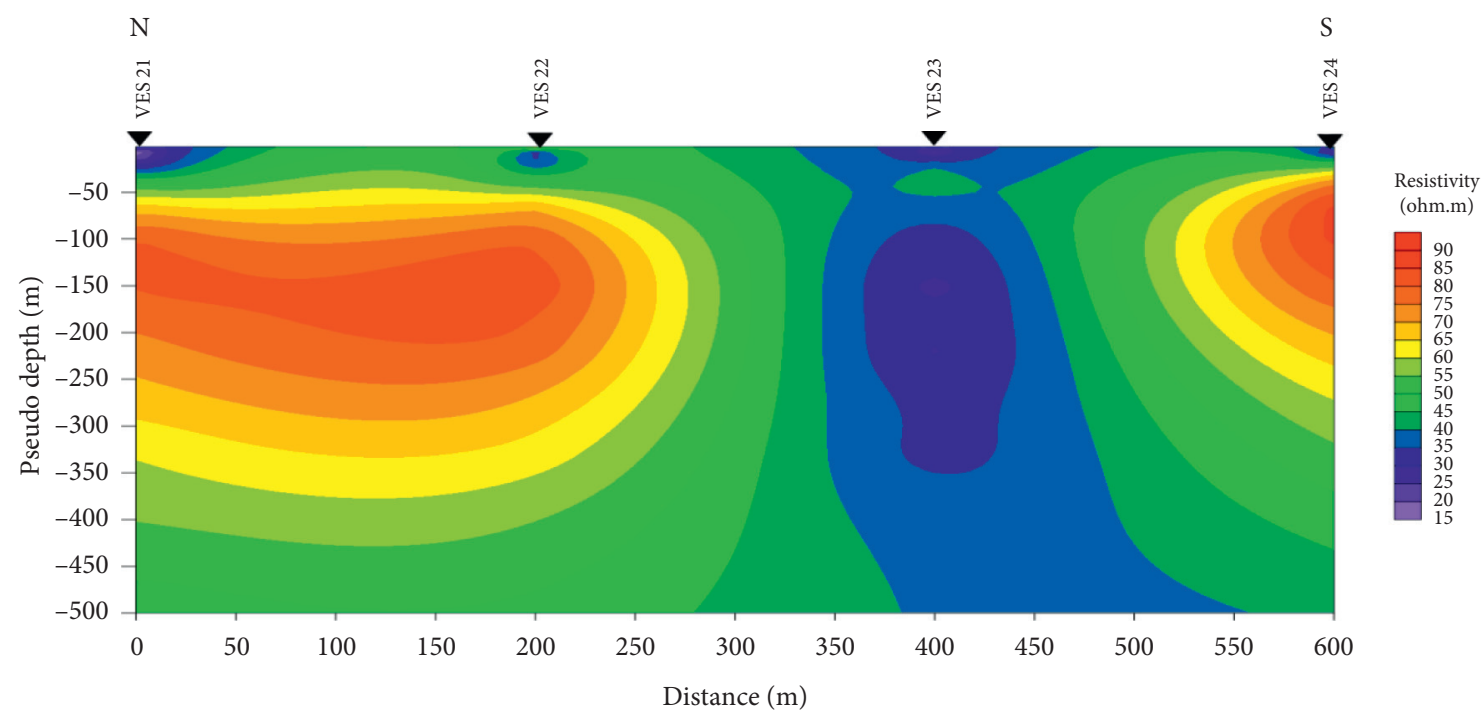

Figure 9: Pseudosections along with profile two.

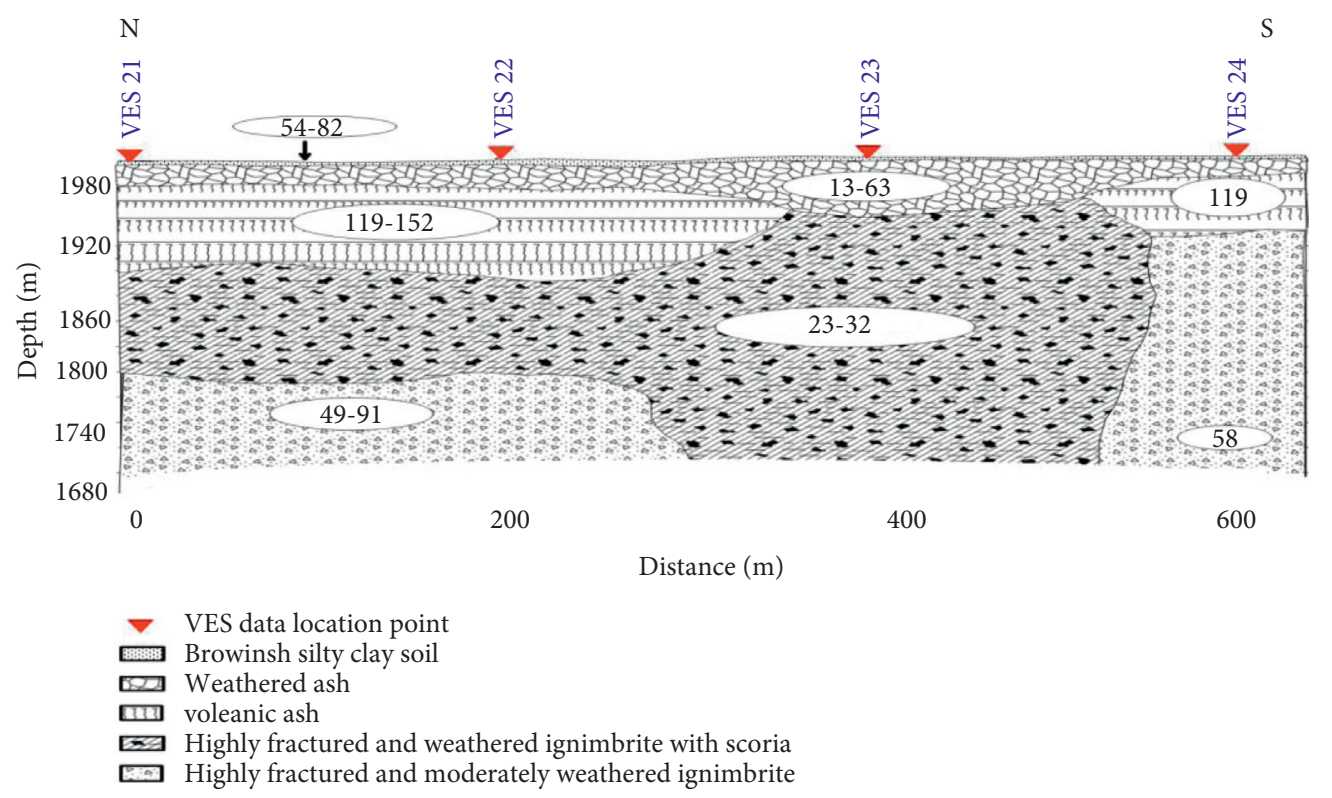

FIGURE 10: Geoelectric section along with profile two.

3.6. Total Magnetic Intensity Field Anomaly. The total magnetic field anomaly map was created after diurnal corrections and removal of the IGRF value from the field data. This map shows that a relatively low magnetic response was observed north-northeast towards the northwestern part of the study area, whereas the high magnetic response is observed at the northeastern, east central, and northeast margin of the map. From Figure 11, the map observed that the anomaly of total magnetic field intensity variation started from $21229 \mathrm{nT}-35491 \mathrm{nT}$.

3.7. Analytical Signal Map Anomaly. Analytical signal of the total magnetic field reduces the magnetic data to anomalies whose maximum marks the edges of the magnetized bodies if the sources are resolved. The analytical signal map is very useful for delineating magnetic source location at shallow subsurface levels. The analytical signal is formed through a combination of horizontal and vertical gradients of a magnetic anomaly and has a form over causative bodies that depend on the locations of the bodies but not their directions of magnetization [29]. It can be used to find horizontal locations and depths of magnetic contacts.

The analytical signal map of the study area was produced from the total magnetic field anomaly map. From Figure 12, the observed analytical signal map low amplitudes were located southwest to vertically going upward north-west and east margin of the map. 

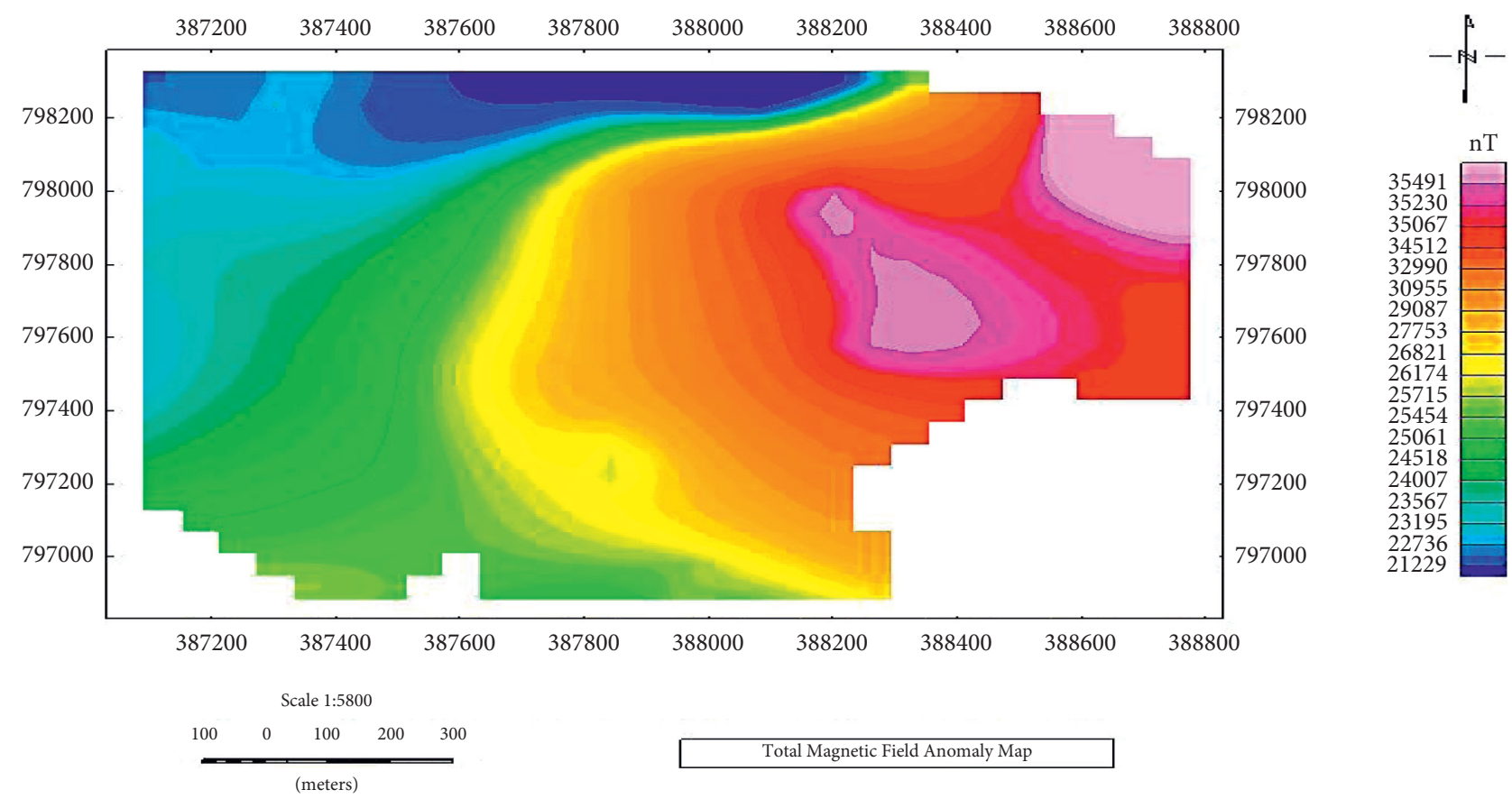

FIGURE 11: Total magnetic field intensity anomaly map of the study area.
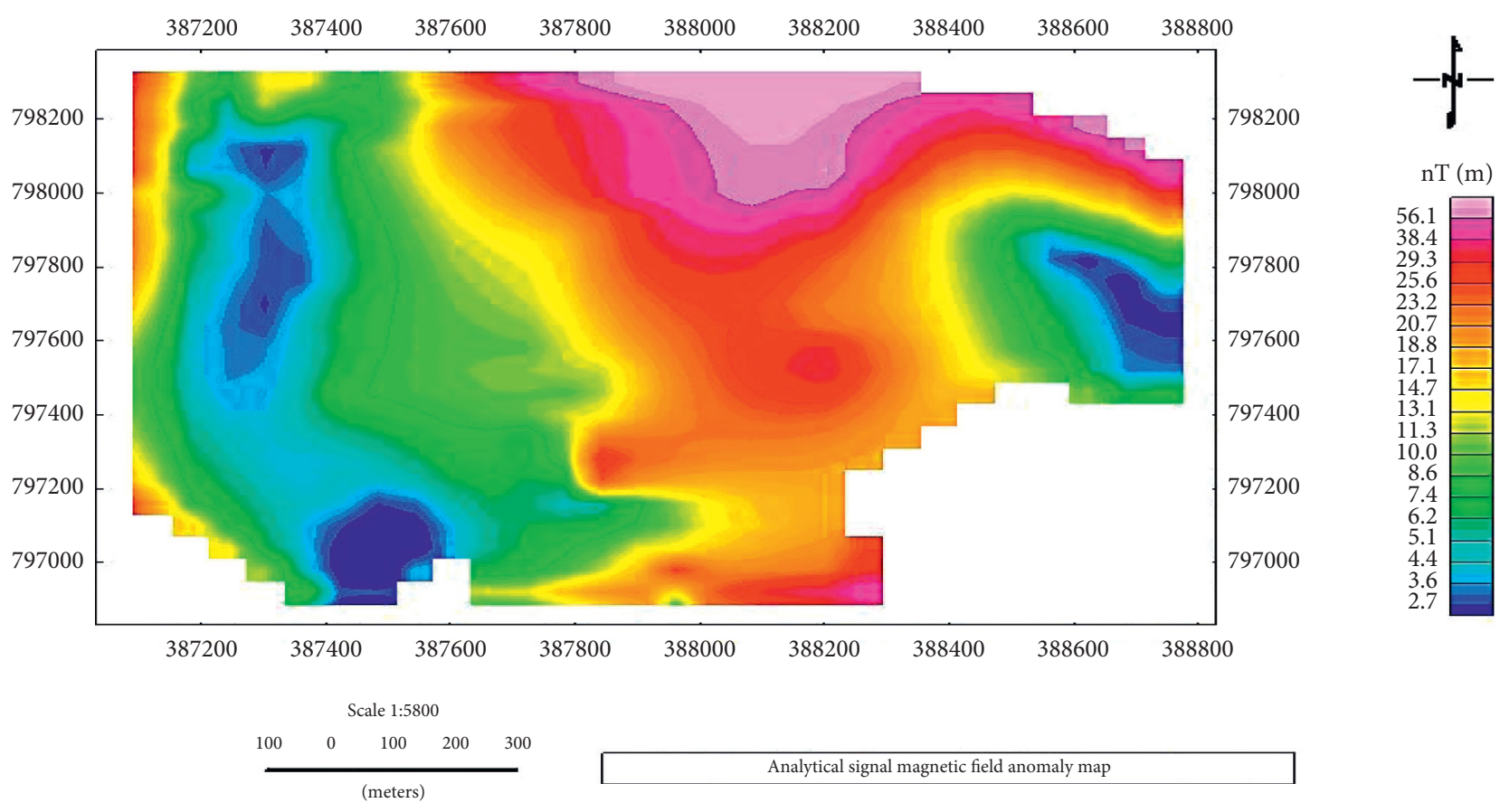

FIGURE 12: Analytical signal magnetic field anomaly maps.

\subsection{Upward Continued Magnetic Field Anomalous Maps.}

(1) All the magnetic maps were made when the magnetic fields were corrected.

(2) Upward continuation filters observed that as continuity increases, the shallow features smoothened and enhanced the detection of deep features. The magnetic field data were gridded and filtered at $0 \mathrm{~m}$ $140 \mathrm{~m}, 280 \mathrm{~m}, 420 \mathrm{~m}$, and $560 \mathrm{~m}$ of upward continuation in the stacked figure (because the depth of borehole was 280 meters, upward continuation detected twice of the depth of borehole).

From the map, it is observed that the field in upward continuation anomaly map values varies from 20000 to 


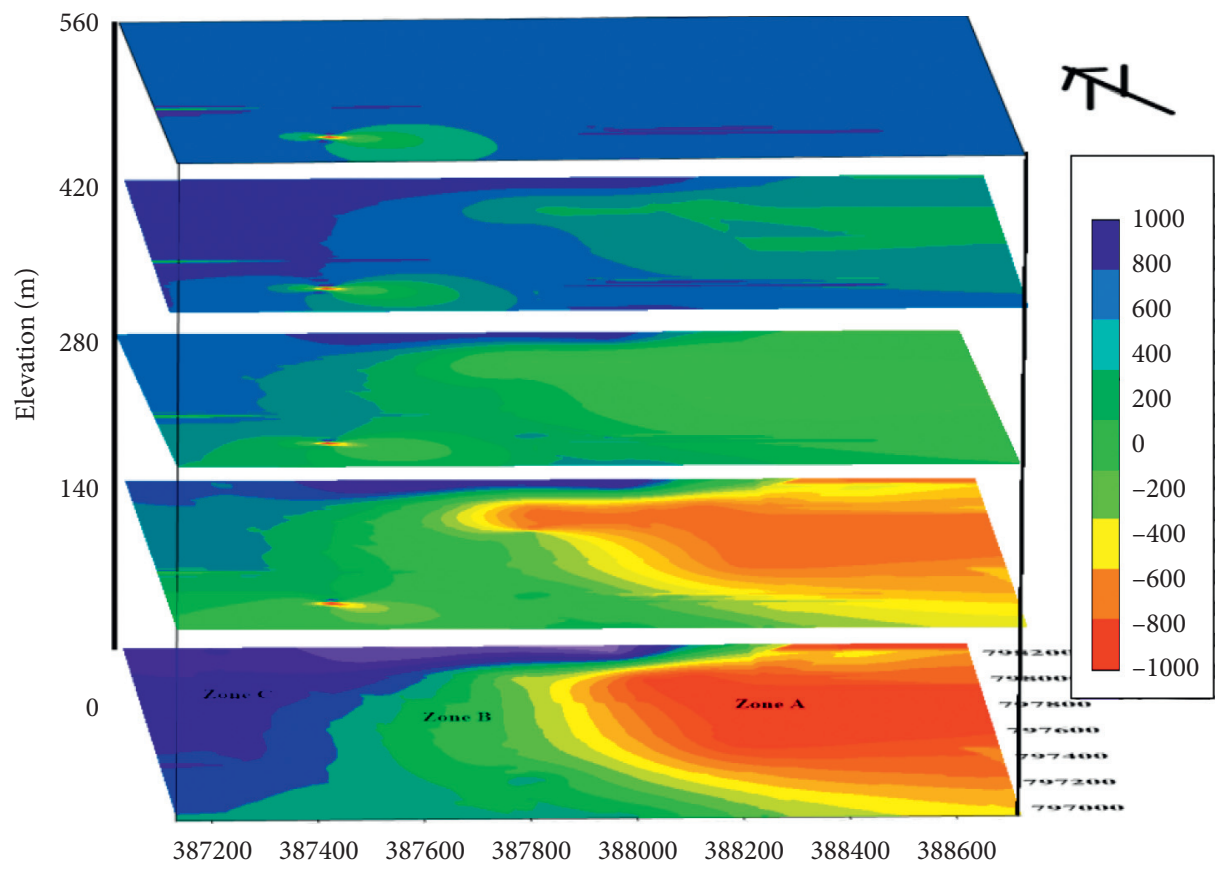

FIGURE 13: Stacked map of upward continuation of magnetic anomaly map.

$36000 \mathrm{nT}$, which is a large variation in the magnetic field, indicating in either lithology or degree of alteration that the study area is located in the main Ethiopia Rift. This, in turn, makes the magnetic field very large (not an abnormal range). This 20000 to $36000 \mathrm{nT}$ is an inclusive number that consists of all gridded and filtered upward continuation.

The upward continued map is an enhancement technique that transforms the observed magnetic field data on a surface to a higher level. Near the surface (high frequency), features are attenuated as the magnetic data are virtually upward [2]. The principle of continuation is the mathematical projection of potential field data (magnetic or gravity) from one datum vertically upwards or downwards to another datum. Effectively, the continuation process simulates the anomaly at levels below or above sea level as if the data had been obtained at those levels.

The continued upward maps of the study area were produced from the total magnetic field map. From Figure 12, upward continuation filters observed that as continuity increases, the shallow features smoothened and enhanced deep features detection. The magnetic field data were gridded and filtered at $0 \mathrm{~m}, 140 \mathrm{~m}, 280 \mathrm{~m}, 420 \mathrm{~m}$, and $560 \mathrm{~m}$ of upward continuation in the next stacked Figure 13.

3.8.1. Zone A. This region can be classified as a high magnetic anomaly that could probably be the responses from rocks that have high magnetic susceptibility. This high magnetic anomaly is observed in the north-east, central-east, and south-eastern parts of the study area. The signature of this anomaly ranges from $-1000 \mathrm{nT}$ to $1000 \mathrm{nT}$.

3.8.2. Zone B. This region is a comparatively low magnetic anomaly, and its magnetic field varies in the range of
$-1000-1000 \mathrm{nT}$. This may be caused by the rocks of low magnetic susceptibility that have resulted in fracturing and weathering of rocks. This low magnetic anomaly zone is trending in the southwest to diagonally going upward to the west-central part of the study area.

3.8.3. Zone C. These low magnetic anomaly areas can be interpreted as rocks that have resulted from the oxidation of the magnetic material due to intense weathering of the rocks unit. This anomaly is observed in the northwestern portion of the study areas. These upward magnetic field anomaly values vary in the interval of -1000 to $1000 \mathrm{nT}$.

\section{Conclusion}

Examining the potential aquifer of profile one's geoelectric section, the horizons of layer four were better potential aquifers as the highly fractured and weathered ignimbrite zone of layer five of VES13 was $219 \mathrm{~m}$ deeper than the depths of the other VES points, and along with profile two geoelectric section, the horizon of layer four VES23 layer five has the lowest resistivity with large thickness at a depth of $252.8 \mathrm{~m}$. Thus, the low resistivity and the large thickness of these formations are an indication of the high yield of groundwater potential in the study area. From total magnetic and upward continuation maps, low magnetic responses are found from southwest to northwestern areas of the study. From this, it may be concluded that the low magnetic anomaly response results from a weak zone and a high degree of weathering and fracturing of rocks formed in the study area. The upward continued magnetic field map anomaly to 560 illustrated that northwestern to the southwest areas have a low magnetic anomaly, which implies the 
presence of highly fractured and weathered ignimbrite in the depth of investigation.

\section{Data Availability}

The data used to support the findings of this study are included within the article.

\section{Disclosure}

Similar presentation of this manuscript is in the thesis titled Groundwater Potential Evaluation Based on Integrated GIS and Remote Sensing Technique, in Bilate River Catchment. The thesis was submitted to the School of Graduate Studies of Addis Ababa University in partial fulfillment of the requirements for the Degree of Master of Science in Geochronology

\section{Conflicts of Interest}

The authors declare that there are no conflicts of interest.

\section{References}

[1] I. Muchingami, A. Mkali, L. Vinqi et al., "Integration of hydrogeophysical and geological investigations in enhancing groundwater potential assessment in Houtriver gneiss crystalline basement formation of South Africa," Physics and Chemistry of the Earth, Parts A/B/C, vol. 123, p. 103009, 2021.

[2] S. Gaikwad, N. J. Pawar, P. Bedse, V. Wagh, and A. Kadam, "Delineation of groundwater potential zones using vertical electrical sounding (VES) in a complex bedrock geological setting of the West Coast of India," Modeling Earth Systems and Environment, vol. 1-15, 2021.

[3] O. B. Olatinsu and S. Y. Salawudeen, "Integrated geophysical investigation of groundwater potential and bedrock structure in Precambrian basement rocks of Ife, southwest Nigeria," Groundwater for Sustainable Development, vol. 14, p. 100616, 2021.

[4] M. A. Adabanija, L. L. Kolawole, A. O. Afolabi, and O. O. Osinowo, "Investigating aquifer structure in a lowlatitude crystalline basement complex of southwestern Nigeria using radial vertical electrical sounding," Arabian Journal of Geosciences, vol. 14, no. 4, pp. 1-14, 2021.

[5] K. A. Ifeanyichukwu, E. Okeyeh, O. E. Agbasi, O. I. Moses, and O. Ben-Owope, "Using geo-electric techniques for vulnerability and groundwater potential analysis of aquifers in nnewi, South eastern Nigeria," Journal of Geology, Geography and Geoecology, vol. 30, no. 1, pp. 43-52, 2021.

[6] T. Shang, Z. Xu, X. Gong, X. Li, S. Tian, and Y. Guan, "Application of electrical sounding to determine the spatial distribution of groundwater quality in the coastal area of Jiangsu Province, China," Journal of Hydrology, vol. 599, p. 126348, 2021.

[7] A. Y. Kahal, K. Abdelrahman, H. J. Alfaifi, S. Qaysi, and A. N. Aldossari, "Geophysical assessment of open dumpsite nearby Khamis Mushait industrial zone, southwestern Saudi Arabia," Journal of King Saud University Science, vol. 33, p. 101518, 2021.

[8] M. M. Gobashy, A. M. Metwally, M. Abdelazeem, K. S. Soliman, and A. Abdelhalim, "Geophysical exploration of shallow groundwater aquifers in arid regions: a case study of siwa oasis, Egypt," Natural Resources Research, vol. 30, 2021.

[9] E. S. Joel, P. I. Olasehinde, T. A. Adagunodo et al., "Geoinvestigation on groundwater control in some parts of Ogun state using data from Shuttle Radar Topography Mission and vertical electrical soundings," Heliyon, vol. 6, no. 1, p. e03327, 2020.

[10] S.-C. Chang and C.-T. Lee, "Evaluation of the trend of air quality in Taipei, Taiwan from 1994 to 2003," Environmental Monitoring and Assessment, vol. 127, no. 1-3, pp. 87-96, 2007.

[11] Q. Yin, J. Wang, M. Hu, and H. Wong, "Estimation of daily PM 2.5 concentration and its relationship with meteorological conditions in Beijing," Journal of Environmental Sciences, vol. 48, pp. 161-168, 2016.

[12] X. Zhao, X. Zhang, X. Xu, J. Xu, W. Meng, and W. Pu, "Seasonal and diurnal variations of ambient PM2.5 concentration in urban and rural environments in Beijing," Atmospheric Environment, vol. 43, no. 18, pp. 2893-2900, 2009.

[13] D. Sinha and J. Dammani, "Seasonal variations in mass concentrations of PM10 and PM2.5 at traffic intersection and residential sites in Raipur city," Research Journal of Chemistry and Environment, vol. 22, pp. 25-31, 2018.

[14] O. Pablo, R. Julieta, Q. Nancy, B. Ariel, and C. Agustin, "Short-term exposure to particulate matter (PM10 and $\mathrm{PM} 2.5)$, nitrogen dioxide (NO2), and ozone (O3) and allcause and cause-specific mortality: systematic review and meta-analysis," Environment International, vol. 142, p. $105876,2020$.

[15] Z. Yunquan, F. Jiaying, M. Feiyue, D. Zan, X. Qianqian, and W. Wei, "Age- and season-specific effects of ambient particles (PM1, PM2.5, and PM10) on daily emergency department visits among two Chinese metropolitan populations," Chemosphere, vol. 246, p. 125723, 2020.

[16] G. Le-Qian, C. Yu, M. Bai-Bing et al., “Ambient air pollution and adverse birth outcomes: a systematic review and metaanalysis," Journal of Zhejiang University-Science B, vol. 20, pp. 238-252, 2019.

[17] Z. Yunquan, D. Zan, X. Qianqian, W. Wei, H. Li, and M. Feiyue, "Short-term effects of ambient PM1 and PM2.5 air pollution on hospital admission for respiratory diseases: casecrossover evidence from Shenzhen, China," International Journal of Hygiene and Environmental Health, vol. 224, p. 113418, 2020.

[18] W.-K. Jo and J.-H. Park, "Characteristics of roadside air pollution in Korean metropolitan city (Daegu) over last 5 to 6 years: temporal variations, standard exceedances, and dependence on meteorological conditions," Chemosphere, vol. 59, no. 11, pp. 1557-1573, 2005.

[19] A. P. Kesarkar, M. Dalvi, A. Kaginalkar, and A. Ojha, "Coupling of the Weather Research and Forecasting model with AERMOD for pollutant dispersion modeling. A case study for PM10 dispersion over Pune, India," Atmospheric Environment, vol. 41, no. 9, pp. 1976-1988, 2007.

[20] Y. Yu, R. S. Sokhi, N. Kitwiroon, D. R. Middleton, and B. Fisher, "Performance characteristics of MM5-SMOKECMAQ for a summer photochemical episode in southeast England, United Kingdom," Atmospheric Environment, vol. 42, no. 20, pp. 4870-4883, 2008.

[21] J. Fu, C. Jang, D. Streets et al., "MICS-Asia II: modeling gaseous pollutants and evaluating an advanced modeling system over East Asia," Atmospheric Environment, vol. 42, no. 15, pp. 3571-3583, 2008. 
[22] R. Krishnaraj, "Control of pollution emitted by foundries," Environmental Chemistry Letters, vol. 13, no. 2, pp. 149-156, 2015.

[23] J. Su, P. Zhao, J. Ding, X. Du, and Y. Dou, "Insights into measurements of water-soluble ions in PM2. 5 and their gaseous precursors in Beijing," Journal of Environmental Sciences, vol. 102, pp. 123-137, 2021.

[24] R. Krishnaraj, "Contemporary and futuristic views of pollution control devices in foundries," Ecotoxicology and Environmental Safety, vol. 120, pp. 130-135, 2015.

[25] W. Guanglong, S. Yangzhao, X. Jiahong, and L. Yong, "Research on pollution prevention and control BAT of PCDD/Fs in secondary copper industry," Ecotoxicology and Environmental Safety, vol. 181, pp. 308-311, 2019.

[26] J. Liu, T. Wu, Q. Liu, S. Wu, and J.-C. Chen, "Air pollution exposure and adverse sleep health across the life course: a systematic review," Environmental Pollution, vol. 262, p. 114263, 2020.

[27] K. Selvakumar and M. Y. Kim, "A numerical study on the fluid flow and thermal characteristics inside the scrubber with water injection," Journal of Mechanical Science and Technology, vol. 30, no. 2, pp. 915-923, 2016.

[28] S. Arya, J. Sottile, and T. Novak, "Numerical modeling of a flooded-bed dust scrubber integrated into a longwall shearer," Mining, Metallurgy \& Exploration, vol. 37, no. 4, pp. 11051119, 2020.

[29] A. Bari, V. A. Dutkiewicz, C. D. Judd, L. R. Wilson, D. Luttinger, and L. Husain, "Regional sources of particulate sulfate, SO2, PM2.5, $\mathrm{HCl}$, and $\mathrm{HNO} 3$, in New York, NY," Atmospheric Environment, vol. 37, no. 20, pp. 2837-2844, 2003.

[30] A. G. Bhave, D. K. Vyas, and J. B. Patel, "A wet packed bed scrubber-based producer gas cooling-cleaning system," Renewable Energy, vol. 33, no. 7, pp. 1716-1720, 2008.

[31] P. F. Biard, A. Couvert, C. Renner, and J. P. Levasseur, "Assessment and optimisation of VOC mass transfer enhancement by advanced oxidation process in a compact wet scrubber," Chemosphere, vol. 77, pp. 182-7, 2009. 